\title{
Phasic, Nonsynaptic GABA-A Receptor-Mediated Inhibition Entrains Thalamocortical Oscillations
}

\author{
Zita Rovó, ${ }^{1,2 \star}$ Ferenc Mátyás, ${ }^{1 \star}$ Péter Barthó, ${ }^{1}$ Andrea Slézia, ${ }^{1}$ Sandro Lecci, ${ }^{2}$ Chiara Pellegrini, ${ }^{2}$ Simone Astori, ${ }^{2}$ \\ Csaba Dávid, ${ }^{1}$ Balázs Hangya, ${ }^{3,4}$ Anita Lüthi, ${ }^{2}$ and László Acsády ${ }^{1}$ \\ ${ }^{1}$ Laboratory of Thalamus Research, Institute of Experimental Medicine, Hungarian Academy of Sciences, Budapest H-1083, Hungary, ${ }^{2}$ Department of \\ Fundamental Neurosciences, University of Lausanne, Lausanne CH-1005, Switzerland, ${ }^{3}$ Cold Spring Harbor Laboratory, Cold Spring Harbor, New York \\ 11724, and ${ }^{4}$ Laboratory of Cerebral Cortex Research, Institute of Experimental Medicine, Hungarian Academy of Sciences, Budapest H-1083, Hungary
}

GABA-A receptors (GABA-ARs) are typically expressed at synaptic or nonsynaptic sites mediating phasic and tonic inhibition, respectively. These two forms of inhibition conjointly control various network oscillations. To disentangle their roles in thalamocortical rhythms, we focally deleted synaptic, $\gamma 2$ subunit-containing GABA-ARs in the thalamus using viral intervention in mice. After successful removal of $\gamma 2$ subunit clusters, spontaneous and evoked GABAergic synaptic currents disappeared in thalamocortical cells when the presynaptic, reticular thalamic (nRT) neurons fired in tonic mode. However, when nRT cells fired in burst mode, slow phasic GABA-ARmediated events persisted, indicating a dynamic, burst-specific recruitment of nonsynaptic GABA-ARs. In vivo, removal of synaptic GABA-ARs reduced the firing of individual thalamocortical cells but did not abolish slow oscillations or sleep spindles. We conclude that nonsynaptic GABA-ARs are recruited in a phasic manner specifically during burst firing of nRT cells and provide sufficient GABA-AR activation to control major thalamocortical oscillations.

\section{Introduction}

A wealth of data indicate a major role of GABAergic cells in pacing various rhythms via GABA-A receptors (GABA-ARs) in the cortex (Sanchez-Vives and McCormick, 2000; Blatow et al., 2003), hippocampus (Cobb et al., 1995; Wulff et al., 2009), and thalamus (von Krosigk et al., 1993). GABA-ARs are classified into two fundamentally distinct types of receptors, synaptic and extrasynaptic receptors that mediate phasic and tonic inhibition,

Received 0ct. 14, 2013; revised March 12, 2014; accepted April 13, 2014.

Author contributions: A.L. and L.A. designed research; Z.R., F.M., P.B., A.S., S.L., C.P., S.A., and C.D. performed research; Z.R., F.M., P.B., S.L., C.P., S.A., C.D., B.H., A.L., and L.A. analyzed data; Z.R., F.M., A.L., and L.A. wrote the paper.

This work was supported by SciEX-NMS, Swiss National Science Foundation, Foundation 450ème, Hungarian Eötvös Scholarship, Hungarian Scientific Research Fund (0TKA NF101773, T109754) and the National Office for Research and Technology (NKTH-ANR, Neurogen). F.M. and P.B. are János Bolyai Research fellows. S.A. is a Swiss National Science Foundation Ambizione Fellow. B.H. received support from the Swartz Foundation and Marie Curie International Outgoing Fellowship within the EU Seventh Framework Programme for Research and Technological Development. We are grateful to Werner Sieghart for providing primary antibodies and Barna Dudok for providing secondary antibodies. The excellent technical help of Krisztina Faddi is gratefully acknowledged. The authors wish to thank László Barna, the Nikon Microscopy Center at IEM, Nikon Austria GmbH and Auro-Science Consulting Ltd for kindly providing microscopy support. We would also like to thank Prof. William Wisden and Peer Wulff for providing the GABAAR $\gamma 277 \|_{0 x}$ mice.

The authors declare no competing financial interests.

*Z.R. and F.M. contributed equally to this work.

This article is freely available online through the J Neurosci Author Open Choice option.

Correspondence should be addressed to either of the following: Dr. László Acsády, Laboratory of Thalamus Research, Institute of Experimental Medicine, Hungarian Academy of Sciences, PO Box 67, 1450 Budapest, Hungary, E-mail: acsady@koki.hu; or Dr. Anita Lüthi, Department of Fundamental Neurosciences, University of Lausanne, Bugnon 9, CH-1005, Lausanne, Switzerland, E-mail: anita.luthi@unil.ch.

DOI:10.1523/JNEUROSCI.4386-13.2014

Copyright @ 2014 Rovó, Mátyás et al.

This is an Open Access article distributed under the terms of the Creative Commons Attribution License (http://creativecommons.org/licenses/by/3.0), which permits unrestricted use, distribution and reproduction in any medium provided that the original work is properly attributed. respectively. Exactly what type of inhibition governs oscillatory activity is presently unclear. The pentameric GABA-ARs can be assembled in theoretically limitless combinations with various types of subunits (Farrant and Nusser, 2005). For the synaptic clustering of GABA-ARs, the $\gamma 2$ subunit is essential (Essrich et al., 1998). Receptors containing the $\gamma 2$ subunit typically have rapid kinetics, low sensitivity to GABA, and prompt desensitization, enabling them to conduct fast inhibitory postsynaptic events, typical for phasic inhibition (Brickley et al., 1999). GABA-ARs containing $\delta$ instead of $\gamma$ subunits are abundant in extrasynaptic membranes (Nusser et al., 1998; Wei et al., 2003; Farrant and Nusser, 2005; Belelli et al., 2009), have higher sensitivity to GABA, and are activated by ambient GABA. These extrasynaptic receptors are primarily responsible for a slow, persistent (i.e., tonic) chloride current (Hamann et al., 2002; Wei et al., 2003; Cope et al., 2005; Bright et al., 2007, 2011).

More recently, evidence is accumulating for a third type of GABA-AR-triggered inhibition. This spillover-mediated transmission is caused by diffusion of GABA from the synaptic cleft and allows activation of GABA-ARs in extrasynaptic locations (Capogna and Pearce, 2011), resulting in phasic inhibition with slowed-down kinetics. The time course and amplitude of synaptic inhibition are an important determinant of the oscillation frequency; therefore, it is critical to determine the contribution of these three types of GABA-AR-mediated inhibition to naturally occurring brain rhythms.

Thalamus is one of the brain regions abundantly expressing both synaptic and extrasynaptic receptors and it is known to be involved in large-scale brain oscillations important for states of vigilance, notably sleep. Thalamocortical (TC) cells express only a few of the potential combinations of GABA-AR subunits 
(Pirker et al., 2000). Synaptic receptors mainly incorporate $\alpha 1$, $\beta 2 / 3$, and $\gamma 2$ subunits, whereas nonsynaptic receptors contain $\alpha 4, \beta 2 / 3$, and $\delta$ subunits. Major pacemakers for rhythms in thalamic circuits are the GABAergic cells of the nucleus reticularis thalami (nRT). Recent in vitro data indicate that extrasynaptic receptors can be recruited during nRT-mediated phasic IPSCs (Herd et al., 2013). This raises the possibility that sleep-related oscillations are partially driven by a population of molecularly distinct GABA-ARs located outside the synapse. However, whether and to what extent phasic activation of extrasynaptic GABA-ARs is capable of driving normal rhythms in vivo are not clear. As many sedative-hypnotic agents target synaptic GABAARs (Winsky-Sommerer, 2009), elucidating the contribution of nonsynaptic GABA-Rs to sleep oscillations is of great interest for further drug development. In this study, we unraveled a significant role for extrasynaptic receptors in sleep oscillations by using localized, virus-mediated gene-knock-out of synaptic $\gamma 2$-GABAARs in the thalamus, leaving only extrasynaptic inhibition intact.

\section{Materials and Methods}

Mice and stereotactic surgery. Adult GABAAR $\gamma 2^{77 \mathrm{I}}$ lox and C57BL/6 J mice from both genders were used for the experiments. Mice were entrained to a $12 \mathrm{~h} \mathrm{light/dark} \mathrm{cycle} \mathrm{with} \mathrm{food} \mathrm{and} \mathrm{water} \mathrm{available} \mathrm{ad} \mathrm{libitum.} \mathrm{All}$ experimental procedures were performed according to the ethical guidelines of the Institute of Experimental Medicine of the Hungarian Academy of Sciences and the University of Lausanne and approved by the local Ethical Committees and Veterinary Offices of the Canton de Vaud. Surgeries and experiments were done under ketamine/xylazine anesthesia (ketamine, $83 \mathrm{mg} / \mathrm{kg}$; xylazine, $3.3 \mathrm{mg} / \mathrm{kg}$ ), except in animals where spindles were recorded. In the latter cases, urethane $(0.012-0.015 \mathrm{~g} / 100 \mathrm{~g}$ body weight) was used as anesthetic. AAV2/1-CMV-CRE (AAV-Cre) and/or AAV2/1-CMV-eGFP (AAV-GFP) viruses (100-300 nl; $10^{12} \mathrm{GC} /$ $\mathrm{ml}$; Vector Biolabs) were injected at a rate of $50-100 \mathrm{nl} / \mathrm{min}$ into the somatosensory thalamus (from bregma: anteroposterior -1.6 to $1.9 \mathrm{~mm}$ and mediolateral $1.4-1.8 \mathrm{~mm}$; dorsoventral $2.8-3.2$ from the surface).

Histology and immunocytochemistry. Animals were transcardially perfused first with saline, then with $\sim 150 \mathrm{ml}$ of fixative solution containing $2 \%-4 \%$ PFA in $0.1 \mathrm{M}$ phosphate buffer (PB). Tissue blocks were cut on a Vibratome (Leica) into $50 \mu \mathrm{m}$ coronal sections. After extensive washes and incubation in blocking solution containing $10 \%$ of normal goat serum or donkey serum and $0.5 \%$ Triton-X, recorded and labeled TC cells were visualized using streptavidin-conjugated fluorescent immunoglobulin tagged with a fluorescent protein (Cy3 or Alexa-488; in 1:2000 for $2 \mathrm{~h}$ at room temperature) or avidin-biotin complex (Vector Laboratories; 1:300, $2 \mathrm{~h}$ ) developed by nickel-intensified diaminobenzidine, as a chromogen. Identifying the phenotype of the recorded cells, anti-Cre recombinase fluorescent staining was performed using monoclonal mouse anti-Cre antibody (Millipore; 1:3000, overnight at room temperature) and with Cy3-(Jackson ImmunoResearch Laboratories) or Alexa488-conjugated anti-mouse secondary antibody (Invitrogen) (1:500; $2 \mathrm{~h}$ at room temperature). For precise localization of the recorded cells or the silicon probe tracks, vesicular glutamate transporter type 2 (vGluT2; guinea pig or mouse anti-vGluT2, 1:3000, Millipore) or parvalbumin (rabbit anti-PV; 1:3000, Baimbridge) counterstaining was used and labeled with Cy5or A647-conjugated secondary antibodies. In control animals, the counterstaining was performed using ImmPRESS anti-mouse or rabbit IG Polymer detection kit.

In vitro biocytin-labeled cells were visualized following one of the above-described protocols. The fixative solution contained 2\% of PFA ( $\sim 150 \mathrm{ml}$ per animal); $50 \mu \mathrm{m}$ coronal sections were cut, washed, cryoprotected in $30 \%$ sucrose in $0.1 \mathrm{M} \mathrm{PB}$ overnight, and freeze thawed over liquid nitrogen. For simple fluorescent double stainings, after incubating the sections in blocking solution (10\% normal goat serum for $30 \mathrm{~min}$ ), sections were treated with monoclonal anti-Cre antibody raised in mouse or rabbit (1:30,000 and 1:12,000; Millipore and Covance, respectively; overnight at room temperature) and one of the following antibodies: mouse anti-NeuN (1:3000, Millipore Bioscience Research Reagents), mouse anti-gephyrin (1:1000, Synaptic System), anti-GABA transporter type 1 (GAT1, Millipore) and type 3 (GAT3, Millipore) overnight at room temperature. The primer antibodies were visualized with corresponding fluorescent secondary antibodies (Alexa-488-, -Cy3-, or -Cy5conjugated IGs). Finally, sections were mounted on slides and covered with Vectashield (Vector Laboratories).

For the visualization of GABA-AR subunits after the treatment with one of the anti-Cre antibodies, the sections were treated with biotinylated goat anti-mouse or -rabbit secondary antibody (1:300, at room temperature for $2 \mathrm{~h}$ ) and amplified with Tyramide (Invitrogen, 1:50, $15 \mathrm{~min}$ ). Next, the sections were digested in pepsin $(0.2-0.3 \mathrm{mg} / \mathrm{ml}$ in $20 \% \mathrm{HCl}$ solution made with $0.1 \mathrm{M} \mathrm{PB} ; 7 \mathrm{~min}$ at $\left.37^{\circ} \mathrm{C}\right)$, then incubated in rabbit anti- $\gamma 2(1: 4000$, Synaptic System), rabbit anti- $\alpha 1$ (1:500, W. Sieghart, Brain Research Institute, Vienna, Austria), or guinea-pig anti- $\alpha 1$ (1:500, Frontier Institute) or rabbit anti- $\alpha 4$ (1:500, W. Sieghart, Brain Research Institute, Vienna, Austria) overnight at room temperature. The Cre immunostaining was visualized with streptavidin-conjugated Alexa-488, while the other antibodies with corresponding $\mathrm{Cy} 3$ or Cy5-conjugated secondary IGs (at room temperature for $2 \mathrm{~h}$ ). Finally, the sections were mounted.

Photographs were taken using either Zeiss Axioplan 2 equipped with DP70 digital camera (Olympus), Olympus FluoView FV1000 or Nikon ECLIPSE Ni-E confocal laser scanning systems. For the quantitative receptor localization, AAV-Cre $(n=4)$ and AAV-GFP $(n=4)$ injected animals were used. In each animal, 3-33 regions of interest (ROIs, area $23,000-30,0000 \mu \mathrm{m}^{2}$ ) were analyzed. To determine the abundance of GABA-AR subunits, the images were thresholded and gray values of pixels were registered in ROIs defined in appropriate optical sections of image stacks in FIJI (Schindelin et al., 2012); then the data were exported to a spreadsheet. For the preparation of figures, when necessary, brightness and contrast were adjusted using Adobe Photoshop CS4 (Adobe Systems) applied to whole images only.

For data acquisition of Stochastic Optical Reconstruction Microscopy (STORM) images, the method described by Dani et al., 2010 was used; 20 $\mu \mathrm{m}$ sections (without freeze thawing) were treated similarly as described above with the following exceptions. Normal horse serum (10\%) was used for blocking, the pepsin-digestion step was shorter ( $3 \mathrm{~min}$ ), and fluorescent secondary antibodies, specific for STORM, were used: horse anti-rabbit Alexa-405/Alexa-647 (1:50; generous gift from B. Dudok, Institute of Experimental Medicine, Budapest, Hungary) visualizing the GABAergic axonal varicosities labeled via guinea-pig antivesicular GABA transporter (vGAT, 1:6000, Synaptic System) and horse anti-guinea-pigCY3/A647 (1:50; generous gift from B. Dudok) marking the $\gamma 2$ content of the postsynaptic elements. Finally, the sections were placed on coverslips, uncovered, and stored at $4^{\circ} \mathrm{C}$. Directly before image acquisition, sections were mounted with a freshly prepared STORM-specific medium containing $80 \mu \mathrm{l}$ of $1 \mathrm{~m}$ DPBS (Sigma-Aldrich), $10 \mu \mathrm{l} 0.5 \mathrm{M}$ mercaptoethylamine, $\mathrm{pH} 8.5,1 \mu \mathrm{l}$ of an antibleaching oxygen scavenger that consists of $10 \mathrm{mg}$ glucose oxidase, $32 \mu \mathrm{l}$ catalase, and $93 \mu \mathrm{l}$ DPBS, and finally $20 \mu \mathrm{l}$ of $30 \%$ glucose in distilled water. For STORM image acquisition, a similar protocol was used as described previously (Dani et al., 2010) with a $100 \times$ objective (CFI Apo $100 \times$ oil NA 1.49 TIRF WD 0.12 ) and imaging cycles containing one frame of activation laser illumination ( 405 or $561 \mathrm{~nm}$ ) followed by three frames of imaging laser illumination $(647 \mathrm{~nm})$ at 30 frames/s. To ensure the $z$-axis stability of data acquisition, Nikon Perfect Focus System was used. Image acquisition was controlled via a STORM Andor camera (iXon 897 backilluminated EMCCD). The STORM images comprised of 1000-3000 cycles were taken using Nikon-STORM-C2 system using Nikon NISElements 4.01 STORM 2.0 software. An automated algorithm was used to subtract channel crosstalk and nonspecific activation of the A647 reporter in multicolor images.

In vitro electrophysiology. For whole-cell patch-clamp recordings, mice (P26-P41) were killed after 1-3 weeks of viral injection. Animals were unilaterally injected with AAV-Cre/AAV-GFP or AAV-GFP (as controls) for all experiments as described above. The brains were quickly removed after brief isoflurane anesthesia and horizontal slices $(300 \mu \mathrm{m})$ containing the ventrobasal complex (VB) and nRT were cut on a vibratome and transferred to a holding chamber containing oxygenated aCSF solution with $2 \mathrm{~mm}$ of divalent cations $\left(\mathrm{CaCl}_{2}, \mathrm{MgCl}_{2}\right)$, myo-inositol (3 mM), and 

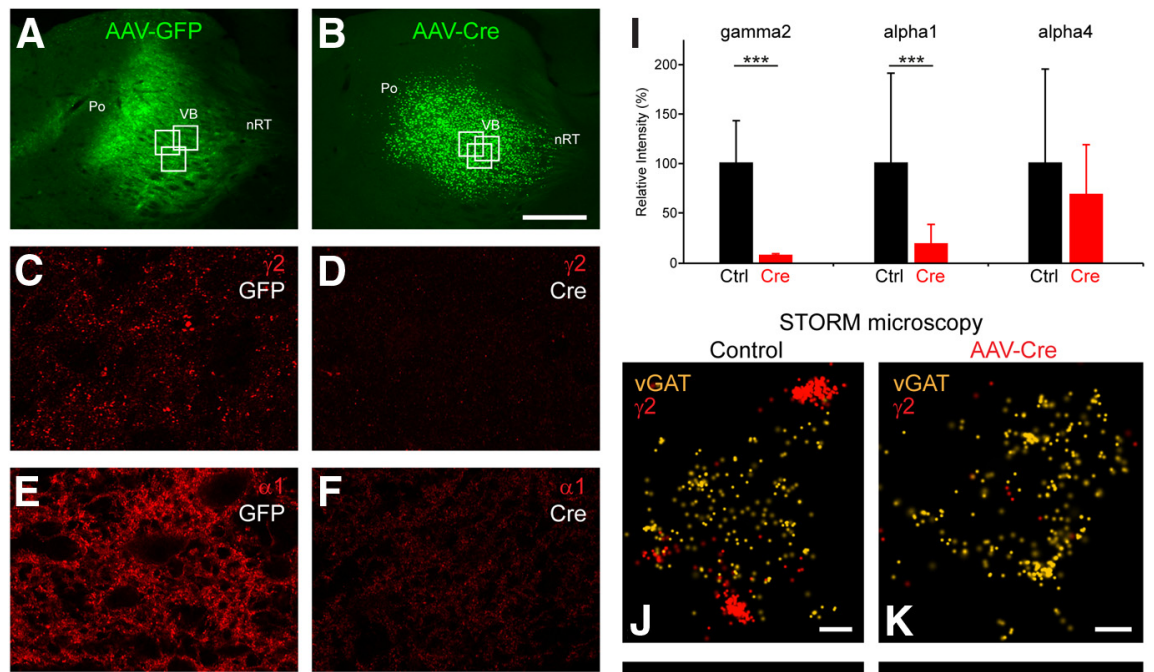

STORM microscopy
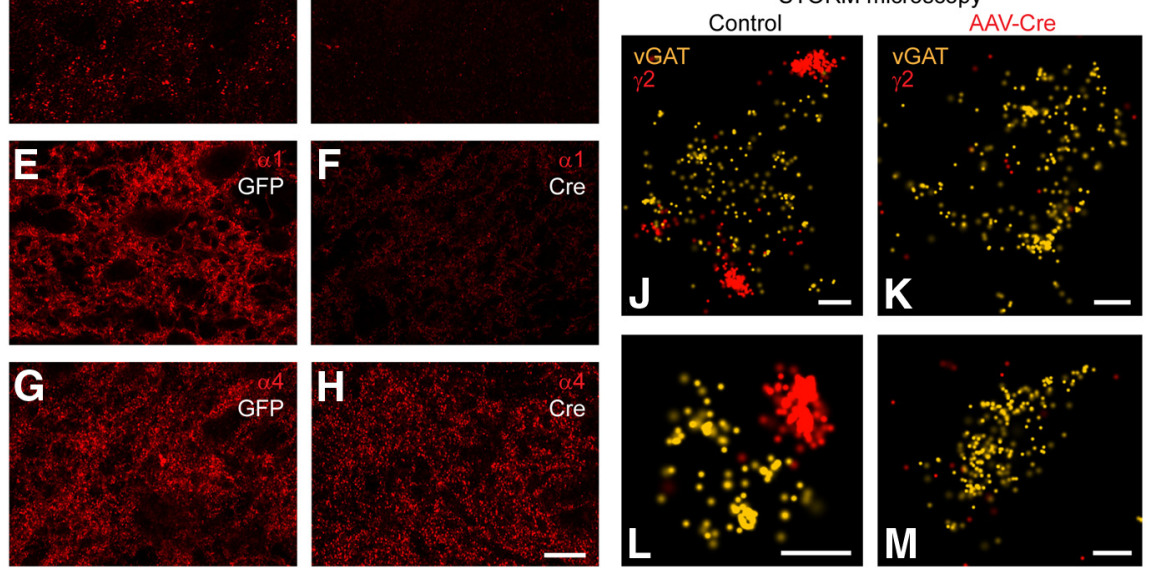

Figure 1. Selective removal of synaptic GABA-AR $\gamma 2$ subunits in the thalamus. $A, B$, Low-power confocal images showing the injection sites of the AAV-GFP (as control) and AAV-Cre viruses in mice somatosensory thalami. White framed areas represent the position of images shown in $\mathbf{C}-\boldsymbol{H}$, which depicts immunostaining for GABA-AR subunits in this and neighboring sections. $\boldsymbol{C}, \boldsymbol{D}$, High-power confocal images of $\gamma 2$ subunit immunostaining in the thalamus. The punctate receptor staining present in the AAV-GFP-infected thalamus $(\boldsymbol{C})$ is not detectable in the AAV-Cre-infected thalamus $(\boldsymbol{D}) 3$ weeks after the viral injections. $\boldsymbol{E}, \boldsymbol{F}$, Large decrease in the density of $\alpha 1$ immunostaining can be observed in the AAV-Cre-infected thalamus $(\boldsymbol{F})$ compared with control $(\boldsymbol{E})$. $\boldsymbol{G}, \boldsymbol{H}$, No visible difference can be seen after $\alpha 4$ subunit immunostaining in the same animal. Quantitative analysis for the density of $\gamma 2, \alpha 1$, and $\alpha 4$ subunits after viral interventions. Bars represent the relative intensity of each subunit in the AAV-Cre-injected thalami compared with the controls (see Materials and Methods). ${ }^{* *} p<0.001$ (Student's t test). $J-M$, Localization of $\gamma 2$ subunit clusters (red) in the close vicinity of individual GABAergic terminals (labeled by vGAT immunostaining, yellow) by super-resolution STORM microscopy. The images represent single terminals and the associated receptor clusters. On the contralateral side, multiple $(\boldsymbol{J})$ or single $(\boldsymbol{L})$ receptor clusters flank the GABAergic terminals. Ipsilaterally, however, no receptor cluster can be found $(\boldsymbol{K}, \boldsymbol{M})$. Scale bars: $\boldsymbol{A}, \boldsymbol{B}, 500 \mu \mathrm{m} ; \boldsymbol{C}-\boldsymbol{H}, 10 \mu \mathrm{m} ; \boldsymbol{G}-\boldsymbol{J}, 200 \mathrm{~nm}$.

Na-pyruvate $(2 \mathrm{~mm})$. Slices were kept at $35^{\circ} \mathrm{C}$ for $30 \mathrm{~min}$ and then at room temperature for subsequent incubation. For recordings, slices were transferred to a submerged recording chamber held at room temperature, except for recording evoked IPSCs (eIPSCs), which was done at $34^{\circ} \mathrm{C}$. The bathing solution contained the following (in $\mathrm{mm}$ ): $131 \mathrm{NaCl}$, $2.5 \mathrm{KCl}, 1.25 \mathrm{NaH}_{2} \mathrm{PO}_{4}, 25.6 \mathrm{NaHCO}_{3}, 2 \mathrm{CaCl}_{2}, 1.2 \mathrm{MgCl}_{2}, 18$ glucose, $1.7 \mathrm{~L}(+)$-ascorbic acid, osmolarity 290-300 mOsm, continuously bubbled with $95 \% / 5 \% \mathrm{O}_{2} / \mathrm{CO}_{2}$ and supplemented with additional pharmacological compounds as indicated below.

Virally infected TC regions were visually identified using OptoLED Lite (Cairn Research) fluorescence illumination at $470 \mathrm{~nm}$. Image acquisition was controlled via an Andor EM-CCD camera (Axon DU-897) and Andor Solis imaging software version 4.16. For patching, fluorescent cells were visualized using near-infrared DIC microscopy (BX50WI; Olympus) and recorded with a MultiClamp 700B amplifier driven by Clampex V.10.2 (Molecular Devices). Data were filtered at $2 \mathrm{kHz}$ and acquired at 5 $\mathrm{kHz}$ using pClamp10 software. Patch pipettes were pulled from borosilicate glass (TW150F-4; World Precision Instruments) and fire-polished on a DMZ-Zeitz-Puller. Once whole-cell access was obtained, series resistance was monitored using a $-10 \mathrm{mV}$ test pulse throughout the recording period; cells were included for analysis only if the series resistance was $<20 \mathrm{M} \Omega$ and the change of resistance was $<25 \%$ over the course of the experiment.

For measuring cellular discharge properties in current-clamp conditions, the intracellular pipette solution contained the following (in $\mathrm{mm}$ ): $140 \mathrm{KMeSO}_{4}, 10 \mathrm{KCl}, 10 \mathrm{HEPES}, 0.1 \mathrm{EGTA}, 2 \mathrm{MgCl}_{2}, 4 \mathrm{Mg}$-ATP, 0.2 Na-GTP, and 10 phosphocreatine (306-309 mOsm, pH 7.23). Na-GTP was freshly added daily from concentrated stock solutions, and the
(Brickley and Mody, 2012)

solution was filtered and maintained on ice. A liquid junction potential of $-10 \mathrm{mV}$ was taken into account. Resting membrane potential was measured after gaining whole-cell access. Depolarizing and hyperpolarizing current square pulses were injected into the recorded cells held at different membrane potentials $(-60 \mathrm{mV},-70 \mathrm{mV})$ through $\mathrm{DC}$ injections.

For sIPSC and eIPSC recordings in TC cells and to measure the cell's input resistance, the intracellular pipette solution contained the following (in mM): $120 \mathrm{CsCl}, 10 \mathrm{HEPES}, 2 \mathrm{EGTA}$, $8 \mathrm{NaCl}, 0.2 \mathrm{MgCl}_{2}, 5$ QX-314-Cl, $0.2 \mathrm{Na}-\mathrm{GTP}$, and 10 phosphocreatine ( $295 \mathrm{mOsm}, \mathrm{pH} 7.35)$. QX-314-Cl and Na-GTP were added freshly daily. To isolate inward currents evoked by GABA-AR activation, 6,7-dinitroquinoxaline2,3-dione (DNQX; $40 \mu \mathrm{m}$; Tocris Bioscience) and D,L-2-amino-5-phosphonopentanoic acid (D,L-APV; $100 \mu \mathrm{M}$; Tocris Bioscience) were added to the bath. Spontaneous IPSCs (sIPSCs) were recorded at $-50 \mathrm{mV}$ for at least $5 \mathrm{~min}$. A liquid junction potential $<5 \mathrm{mV}$ was not taken into account.

To measure tonic GABA-ARs currents in TC cells, the GABA-AR blocker gabazine (SR 95531 hydrobromide/ 6-imino-3-(4-methoxyphenyl)-1(6H)-pyridazinebutanoic acid hydrobromide; $10 \mu \mathrm{M}$; Tocris Bioscience) was bath applied for at least 3 min to cells recorded with the patch pipette solutions used for sIPSCs and eIPSCs. Under these recording conditions, differences in holding currents and input resistance between AAV-GFP and AAVCre cells resulted entirely from altered tonic $\mathrm{Cl}^{-}$conductances. The holding current shift was measured as the difference in the holding current before and during drug application. For tonic current measurements, only male animals were used to avoid the disturbing effect of periodic changes in neurosteroid levels

For eIPSCs, a monopolar stimulation electrode filled with ACSF was placed in the nRT in a position radial to the recorded TC cell and the nRT-TC border, and the cells were recorded at $34^{\circ} \mathrm{C}$. Monophasic IPSCs were elicited at 0.2 or $10 \mathrm{~Hz}$ with $250 \mu \mathrm{A}$ stimulation intensity.

For monitoring evoked burst-induced IPSCs (burst IPSCs), patch pipettes contained the current-clamp recording solution supplemented with $2.5 \mathrm{~mm}$ QX 314-Cl. In contrast to monophasic IPSC recordings, the extracellular medium did not contain glutamate receptor antagonists. Outward burst IPSCs were recorded by voltage clamping VB cells at -30 $\mathrm{mV}$. These recording conditions were chosen to promote bursting in nRT cells via glutamatergic synaptic input (Crandall et al., 2010). Burst IPSCs were evoked once every $30-60 \mathrm{~s}$ with $250 \mu \mathrm{A}$ stimulation intensity, and the amplitude and kinetics were measured throughout the experiment. Under these recording/stimulation conditions, GABA-B receptor-mediated responses were negligible and application of CGP 55845 hydrochloride (2 $\mu \mathrm{M}$, Ascent-Abcam) did not change the evoked currents.

For the establishment of $\mathrm{Cl}^{-}$reversal potential, the following intracellular solution was used (in mM): $120 \mathrm{Cs}$ gluconate, $10 \mathrm{CsCl}, 10 \mathrm{HEPES}, 8$ $\mathrm{NaCl}, 0.2$ EGTA, 14 phosphocreatine, $2 \mathrm{Mg}$-ATP, $0.2 \mathrm{Na}-\mathrm{GTP}, \mathrm{pH}$ 7.3. A junction potential $(-10 \mathrm{mV})$ was taken into account.

For evoked thalamic rebound bursts, the current-clamp recording solution was used. The VB cells were held at $-70 \mathrm{mV}$. Previously recorded scaled burst IPSC waveforms obtained from a control and an AAV-Creinfected neuron were applied every $10 \mathrm{~s}$

For histological recovery of recorded cells in vitro, $0.2 \%$ biocytin (Sigma-Aldrich) was included in the recording solution, and the patch 
pipette was carefully withdrawn at the end of the recordings. Slices were immediately transferred to a fixative solution ( $4 \% \mathrm{PFA}$, at $\left.4^{\circ} \mathrm{C}\right)$, fixed for 1-2 $\mathrm{h}$, and intensively washed in $\mathrm{PB}$. Then, slices were embedded into agar $(2 \%)$ and resectioned with Vibratome.

In vitro analysis. Action potential (AP) characteristics in tonic and burst firing mode were analyzed in Clampfit version 10.2. The peak amplitudes from AP threshold, the halfwidths, and the AP afterhyperpolarizations were always determined for the first $\mathrm{AP}$ in a burst discharge or in tonic firing trains.

Analysis of sIPSCs was performed in MiniAnalysis 6.0 (Synaptosoft). Root-mean-square noise was determined in an event-free $60 \mathrm{~ms}$ time window. A minimal peak threshold of at least twice the determined root-mean-square noise was set as detection criterion. When the detection parameters were applied to traces recorded in gabazine, no events could be detected. To estimate the weighted decay time constant $\left(\tau_{\mathrm{w}}\right)$ in control cells, monophasic events with a rise time $<2 \mathrm{~ms}$ were averaged and $\tau_{\mathrm{w}}$ calculated from a weighted average of decay time constants in a biexponential fit, thereby accounting for occasional slow spontaneous events (see Results).

For tonic currents, all-point histograms of amplitude values were generated from $20 \mathrm{~s}$ segments before and during drug application and fitted by single Gaussian distribution.

Off-line analysis of eIPSCs and burst IPSCs was performed using Clampfit version 10.2. and IgorPro 5. Means of 4 successive responses were used for analysis and amplitudes calculated with respect to the baseline before stimulation. Instead of $10 \%-90 \%$ rise time constant, time to peak was determined, as the burst IPSC is a multiphasic event. For comparison of eIPSCs and burst IPSCs, two parameters were determined. Conductances were calculated through dividing peak event amplitudes by the driving force. Decay time courses were quantified using monoexponential fits for eIPSCs in IgorPro. To determine burst IPSC decay, responses were fit with biexponential or monoexponential curves in Igor Pro. Biexponential fits were used for burst IPSCs of AAV-GFP cells to account for the involvement of both synaptic and nonsynaptic current components, whereas AAV-Cre burst IPSCs were fit with a monoexponential time constant. Fits were applied only to traces showing smooth decay without contamination by additional spontaneous synaptic events.

In vivo electrophysiology. In vivo recordings were performed 3-8 weeks after the viral injections. For LFP recordings, we used 16-channel silicon probes lowered in the primary somatosensory cortex ( $\mathrm{S} 1$, anteroposterior 1.2 and mediolateral $3.2 \mathrm{~mm}$ from bregma). Thalamic multiunit activity was monitored via 32 -channel silicon probes using the same coordinate as for the viral injections. Silicon probe signals were highpassed filtered $(0.3 \mathrm{~Hz})$, amplified $(2000 \times)$ by a 64 -channel amplifier, and digitized at $20 \mathrm{kHz}$ with two National Instruments PCI-6259 cards. TC single-unit activity was recorded by glass microelectrodes (in vivo impedance of $10-40 \mathrm{M} \Omega$ ) filled with $0.5 \mathrm{M} \mathrm{NaCl}$ and $2 \%$ neurobiotin (Vector Laboratories). Neuronal signals were amplified by a DC amplifier (Axoclamp 2B, Molecular Devices), further amplified, and filtered between 0.16 and $5 \mathrm{kHz}$ by a signal conditioner (LinearAmp, Supertech). Juxtacellular labeling of the recorded neurons was performed as previously described (Pinault, 1996).

Gabazine (selective GABA-AR blocker; 1 mm; Sigma) was iontophoretically applied using 1-30 $\mathrm{AA}$ current through small diameter glass capillaries (3-5 $\mu \mathrm{m}$ diameter) for $\sim 30 \mathrm{~min}$.

In vivo analysis. All data analysis was performed in MATLAB (MathWorks). Instead of using arbitrary intraburst and interburst parameters for burst detection, a custom-built semiautomatic burst detection method was used as described previously (Slézia et al., 2011). After the identification of bursts, the following firing parameters were determined: mean firing frequency, frequency of the first APs of the bursts (burst frequency), the firing frequency for the intraburst APs (intraburst fre- quency), the average number of spikes in bursts (intraburst spike number), the average duration of bursts measured in milliseconds (burst length), and the number of all APs in bursts relative to the number of all spikes fired (burstiness index).

The slow oscillation frequency for the LFP recordings was calculated via wavelet spectra, Fourier spectra and autocorrelations using a custombuilt MATLAB routine.

Spindle detection and analysis were performed using a custom-built MATLAB routine. Spindles were detected semiautomatically from the thalamic multiunit activity (MUA). After automatic detection, spindles were verified visually, and false detections were deleted.

Polysomnographic recordings and analysis. Surgeries for combined EEG/electromyographic (EMG) recordings and data scoring were performed on adult GABAAR $\gamma 2^{77 \mathrm{I}} l o x$ mice as previously described (Franken et al., 1998). Two weeks before surgery, 4 animals were bilaterally injected with AAV-GFP (as controls) or AAV-Cre. After $10 \mathrm{~d}$ of recovery, the cable was plugged to the connector and mice were allowed an additional week to habituate. Undisturbed sleep-wake behavior was recorded for $48 \mathrm{~h}$. The analog signals were first amplified $(2000 \times)$, and the EEG and EMG signals were high-pass filtered at $0.7 \mathrm{~Hz}$ and $10 \mathrm{~Hz}$, respectively. Signals were digitized at $2 \mathrm{kHz}$ and down-sampled to $200 \mathrm{~Hz}$ through Somnologica 3.3.1 software (Embla System). Data were visually scored with a resolution of $4 \mathrm{~s}$ to determine the vigilance state (wake, NREM sleep, REM sleep). The NREM sleep power spectrum was generated from NREM sleep during both light and dark periods, but NREM sleep epochs were included only if they were both preceded and followed by other NREM sleep epochs (Wimmer et al., 2012). For analysis on spectral characteristics of the NREM-to-REM sleep transitions, only the two light phases were taken into account, as these contain the majority of transitions. Data analysis was performed as described previously (Astori et al., 2011; Wimmer et al., 2012).

Statistics. Statistical significance was assessed using Student's $t$ test or Mann-Whitney $U$ test based on the normality level of the dataset, and $p<0.05$ was considered statistically significant. For quantitative receptor localization, after normalization for area of ROIs and averaging, samples from Cre- and GFP-expressing animals were compared with Student's $t$ test using Mystat (Systat Software). For analysis of EEG power spectra, univariate repeated-measures ANOVA with factor "group" and "bin" was used. In both text and figures, data are presented as mean \pm SD or as whisker plots.

\section{Results}

Viral intervention successfully eliminates synaptic

\section{$\gamma 2$ subunits}

To selectively and focally delete the $\gamma 2$ subunits from TC cells, we unilaterally injected Cre-recombinase-containing or, as control, GFP-containing, adeno-associated viral vectors (AAV-Cre or AAV-GFP, respectively) into the somatosensory thalamus of GABAAR $\gamma 2^{771}$ lox mice (Fig. $1 A, B$ ). After 2-3 weeks, we com- 
A
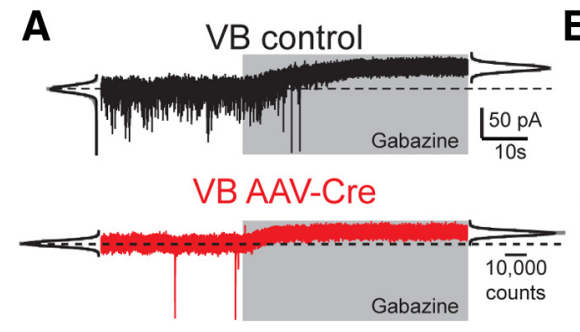

Figure 3. Deletion of synaptic $\gamma 2$ subunits reduces tonic GABAergic inhibition. $\boldsymbol{A}$, Outward shift in the holding current of a TC cell held at $-50 \mathrm{mV}$ before and during gabazine ( $10 \mu \mathrm{m}$, gray shadow) application in a control (top, black) and an AAV-Cre (bottom, red) VB neuron. Gaussian curves indicate a fit to the all-points histograms of current traces before (left) and after (right) gabazine. Dotted horizontal lines indicate mean holding current level before gabazine. The large spontaneous inhibitory events recorded from the AAV-Cre VB cell are discussed in Figure 4. $B$, Bar graph of gabazine-induced increase in the holding current $(\Delta \mathrm{l})$ (control, Ctrl, $n=7$; AAV-Cre, Cre, $n=9$ ). Bars indicate mean \pm SD. ${ }^{*} p<0.05$ (Student's $t$ test). C, Box plot of cellular input resistance $\left(\mathrm{R}_{\mathrm{i}}\right)$ of control $(n=12)$ and AAV-Cre VB cells $(n=27)$. The midline indicates the median. Bottom and top of the boxes represents the first and third quartiles, respectively. Whiskers represent full range. ${ }^{*} p<0.05$ (Student's $t$ test).

pared ipsilateral and contralateral expression of $\gamma 2$ subunits with confocal microscopy. In noninfected as well as the AAV-GFPinfected thalami, $\gamma 2$ immunostaining resulted in dense punctate labeling, reflecting the predominantly synaptic localization of this subunit (Fig. 1C) (Nusser et al., 1998). In contrast, within the AAV-Cre-infected region, punctate $\gamma 2$ immunoreactivity was not apparent (Fig. 1D). Next, we examined the expression of $\alpha 1$ subunits, which coassemble with $\gamma 2$ to form functional receptors (Tretter et al., 1997) but, in addition, are also present extrasynaptically. Compared with controls, $\alpha 1$ labeling was reduced in the AAV-Cre-infected regions, but a weak staining, probably reflecting the extrasynaptic pool, persisted (Fig. 1E,F). Quantitative receptor localization demonstrated a nearly complete loss of $\gamma 2$ immunoreactivity (relative intensity, $6.68 \pm 2.11 \%$ ) and a less dramatic but highly significant decrease in $\alpha 1$ immunostaining (relative intensity, $18.27 \pm 20.18 \%$ ) compared with AAV-GFPinfected regions (Fig. 1I). In contrast, in the case of the extrasynaptic, $\alpha 4$-containing GABA-ARs, which are responsible for tonic inhibition (Porcello et al., 2003; Chandra et al., 2006), no significant difference was observed between the AAV-Cre- and AAV-GFPinfected thalamic regions (relative intensity, $68.24 \pm 50.82 \%$; Fig. $1 G-I)$. Based on these anatomical findings, we conclude that deletion of $\gamma 2$ and the associated $\alpha 1$ protein was successful and selective in the infected regions.

To analyze the changes of $\gamma 2$ staining at higher spatial resolution, STORM was applied (Dani et al., 2010). In these experiments, we used vesicular GABA transporter (vGAT) labeling to visualize GABAergic terminals. On the contralateral side, vGAT immunostaining labeled vesicle aggregations in the size range of nRT terminals (1-2 $\mu \mathrm{m})$. Adjacent to these terminals, $\gamma 2 \mathrm{immu}-$ nostaining formed dense clusters of punctae (Fig. $1 J-L$ ). The size of these clusters (400-500 nm) was in the range of synapses established by nRT terminals measured in serial electron microscopic images (Wanaverbecq et al., 2008). Single vGAT-positive terminals contacted one or up to four receptor clusters. In case of multiple contacts, the synapses were on different sides of the terminals, similar to earlier results (Wanaverbecq et al., 2008) (Fig. $1 J$ ). In contrast to the contralateral side, in the ipsilateral, AAV-Cre-infected region, $\gamma 2$-labeled receptor clusters were absent around the vGAT-positive boutons (Fig. $1 K-M$ ). These data confirm successful viral intervention and the elimination of synaptic GABA-ARs.

\section{Removal of $\gamma 2$ subunits eliminates fast IPSCs}

To test the functional consequences of deletion of synaptic $\gamma 2$ GABA-ARs, we performed whole-cell recordings from VB thalamic neurons in acute horizontal brain slices with intact nRT-TC connections forming the sole inhibitory input. When patched with pipettes containing a $\mathrm{K}^{+}$-based pipette solution (Fig. 2A), these cells showed normal AP discharge properties both in tonic (AP amplitudes $63.1 \pm 11.4 \mathrm{mV}$ and $60.9 \pm 6.1 \mathrm{mV}$; half-widths $1.04 \pm 0.14 \mathrm{~ms}$ and $1.00 \pm 0.18 \mathrm{~ms}$; AP afterhyperpolarization $-21.4 \pm 5.9 \mathrm{mV}$ and $-21.3 \pm 4.2 \mathrm{mV}, p>0.05$ for all values; AAV-GFP, $n=5$; AAV-Cre, $n=9$ ) and burst mode (AP amplitudes $68.2 \pm 9.8 \mathrm{mV}$ and $63.8 \pm 8.1 \mathrm{mV}$; half-widths $0.83 \pm 0.15 \mathrm{~ms}$ and $0.84 \pm 0.23 \mathrm{~ms}$; AP afterhyperpolarization $-13.4 \pm 6.5 \mathrm{mV}$ and $-12.9 \pm 3.0 \mathrm{mV}$; AP number/burst $1.7 \pm$ 0.4 and $1.6 \pm 0.4, p>0.05$ for all values; control, $n=7$; AAV-Cre, $n=8)$. Moreover, cellular resting membrane potentials were unaltered $(-76.6 \pm 9.6 \mathrm{mV}$ vs $-75.0 \pm 11.4 \mathrm{mV}, p>0.05$; control, $n=22$; AAV-Cre, $n=21$ cells).

In the presence of glutamate receptor antagonists (DNQX 40 $\mu \mathrm{M}, \mathrm{D}, \mathrm{L}-\mathrm{APV} 100 \mu \mathrm{M})$, all VB cells recorded in the control slices displayed fast spontaneous IPSCs (sIPSCs; rise time $<2 \mathrm{~ms}$, weighted decay time constant $<11 \mathrm{~ms}$ ) at a frequency of $1.33 \pm$ $0.89 \mathrm{~Hz}$ that were blocked by the GABA-AR antagonist gabazine (Fig. $2 B$ ). In contrast, fast rising sIPSCs were almost completely abolished from VB cells recorded in the AAV-Cre-infected regions $(0.006 \pm 0.018 \mathrm{~Hz}, p<0.001$; Fig. $2 A-C)$. In addition to fast IPSCs, slower (rise time $>30 \mathrm{~ms}$ ) IPSCs were occasionally detected in both groups (see below).

We next examined eIPSCs elicited via activation of GABAergic inputs by extracellular stimulation in the nRT. Fast eIPSCs (rise time $<1 \mathrm{~ms}$, decay time $<4 \mathrm{~ms}$ ) were observed in 4 of 5 control cells tested with a mean amplitude of $-82 \pm 27 \mathrm{pA}$ and $0.19 \pm 0.15 \mathrm{pC}$ of charge transfer. In contrast, in the AAV-Creinfected regions, eIPSCs were absent in 5 of 6 TC cells recorded after both single and $10 \mathrm{~Hz}$ stimulation (Fig. 2D,E). The one AAV-Cre TC cell that responded to the stimulation showed slow kinetics (rise time $5 \mathrm{~ms}$; decay time constant $28 \mathrm{~ms}$ ) and large amplitude ( $-120 \mathrm{pA})$. In summary, these data demonstrate the absence of fast synaptic inhibition mediated by $\gamma 2$-GABA-ARs in AAV-Cre-infected VB cells.

To determine the effect of deleting synaptic receptors on tonic GABA-AR-mediated currents, we applied gabazine $(10 \mu \mathrm{M})$ to cells patched with $\mathrm{Cl}^{-}$-based intracellular solutions. In AAVGFP-infected cells, gabazine induced an outward shift in the holding current $(\Delta \mathrm{I}=53 \pm 19 \mathrm{pA})$, reflecting the presence of a tonic current (Fig. $3 A$ ). In AAV-Cre VB cells, $\Delta \mathrm{I}$ was smaller $(30 \pm 14$ pA, $p<0.05$; Fig. $3 A, B)$ and cellular input resistance was higher compared with controls $(255 \pm 110 \mathrm{M} \Omega$ vs $177 \pm 84$ $\mathrm{M} \Omega, p<0.05$; Fig. $3 C$ ). These results suggest that either $\gamma 2$ GABA-ARs account for a portion of the tonic current or existing extrasynaptic receptors have reduced functionality. More importantly, the fact that tonic currents are reduced in $\gamma 2$-lacking VB cells indicates that a compensatory upregulation of nonsynaptic receptors did not occur.

\section{Burst-mediated IPSCs persist in the absence of synaptic GABA-ARs}

Surprisingly, despite the absence of fast sIPSCs, we observed large and slow spontaneous inhibitory events in slices prepared from both control and AAV-Cre TC cells (Fig. 4A). These typically occurred at low frequencies $(1.9 \pm 3.9 / \mathrm{min}$ vs $1.7 \pm 2.0 / \mathrm{min}, p>$ 0.05; control, $n=16$; AAV-Cre, $n=13$ ), singly or in groups of 2-4 events with interburst intervals of hundreds of milliseconds, 
and are caused by spontaneous repetitive nRT burst discharge (Wimmer et al., 2012). In control cells, these events showed the typical waveform of burst IPSCs consisting of multicomponent fast events riding on a slower current envelope. In contrast, in AAV-Cre TC cells, burst IPSCs consisted of only the slow current envelope and lacked the fast phasic inhibitory currents (Fig. $4 B$ ), showing distinctly slower rising phases.

To quantitatively compare the burst IPSC properties in the two cell groups, we electrically stimulated the nRT to produce evoked burst IPSCs (Fig. 4C,D). Similar to spontaneous burst IPSCs, evoked burst IPSCs were abolished by gabazine (Fig. $4 C)$. Compared with single AP-evoked IPSCs, the evoked burst IPSCs in control cells had a $\sim 9.5$-fold greater conductance (15.3 $\pm 10.0 \mathrm{nS}$ for burst IPSCs, $n=13$, vs $1.63 \pm 0.60 \mathrm{nS}$ for eIPSCs, $n=4)$ and slower decay kinetics (biexponential decay time constants $(\tau 1, \tau 2)$ of $19 \pm 10 \mathrm{~ms}$ and $90 \pm 44 \mathrm{~ms}$ in $n=8$ cells for burst IPSCs, Fig. $4 D$, third panel, vs monoexponential decay time constant $(\tau) 3.0 \pm 1.7$ ms for eIPSCs, $n=4$ ).

Similar to spontaneous burst IPSCs, evoked burst IPSCs were crowned by fast IPSCs in control, but not in AAV-Cre VB cells (Fig. 4C). Moreover, the average amplitude of the evoked burst IPSCs in AAVCre TC cells was diminished by $\sim 60 \%$ compared with control (control, $425 \pm$ $291 \mathrm{pA}, n=13$; AAV-Cre, $161 \pm 93$ pA, $n=20$; $p<0.01$; Fig. $4 D$ ) and burst IPSCs generated in AAV-Cre cells showed decelerated time-to-peak $(33.1 \pm 10.0 \mathrm{~ms}$ in control vs $55.1 \pm 25.9 \mathrm{~ms}$ in AAV-Cre TC cells, $p<0.01$, Fig. $4 D$ ). To compare decay time courses, the slow time constant of AAV-GFP burst IPSCs was compared with a monoexponential fit of the AAV-Cre burst IPSCs, thereby taking into account the lack of a dominant fast current component resulting from the elimination of synaptic receptors. The monoexponential decay time constant of the AAV-Cre burst IPSC was comparable with the slow current component of control cells (AAV-Cre, $\tau=69 \pm 23 \mathrm{~ms}, n=15$, vs control, $\tau 2=90 \pm 44 \mathrm{~ms}, n=8$; $p>0.05$; Fig. $4 D)$. The total charge transfer, calculated as the integral of the current trace, was diminished by $48 \%$ (control, $32.8 \pm 26.5 \mathrm{pC}, n=13$; AAV-Cre, $15.7 \pm 8.3$ pC, $n=20$; $p<0.05$; Fig. $4 D$ ). Moreover, burst IPSCs from both control and AAV-Cre TC cells had a reversal potential corresponding to the $\mathrm{Cl}^{-}$gradient imposed by the patch pipette. These data indicate that, in the absence of synaptic GABA-ARs, significant GABA-AR-mediated, slow, phasic events persist when the presynaptic neurons fire in burst mode. These events are independent of synaptic GABA-ARs and involve phasic recruitment of nonsynaptic GABA-ARs.

The efficiency of burst IPSCs in AAV-Cre VB cells to generate rebound low-threshold spikes could be decreased because of the missing synaptic component and the slowed-down rising phase. To test this, in current-clamped noninfected VB neurons, representative spontaneous burst IPSCs from control or AAV-Cre cells were injected as a command current (Fig. $4 E$ ). Injected wave- forms were scaled in their amplitude (maximal peak $=-420 \mathrm{pA}$ ) to mimic a variety of endogenous inputs of different efficacy. Cells injected with current commands obtained from control or AAV-Cre cells displayed a comparable input-output curve when considering the latency to the first AP in the rebound burst, the amplitude of the low-threshold $\mathrm{Ca}^{2+}$-spike, or the number of elicited APs in response to a given charge injection (Fig. 4F-H). This suggests that, although rebound TC bursting may be weakened because of lower charge transfer in burst IPSCs of AAV-Cre TC cells, rebound bursting is maintained over a considerable range of burst IPSC amplitudes.

\section{Deletion of synaptic GABA-ARs does not produce aberrant oscillation}

Our in vitro data indicate that, after the removal of $\gamma 2$-GABAARs, a sizable portion of the slow burst IPSCs remained intact. To test the role of this slow nonsynaptic current in controlling network rhythms, we used in vivo assays.

We first iontophoretically injected the selective GABA-AR blocker gabazine $(1 \mathrm{mM})$ into the somatosensory thalamus of control mice (Fig. $5 A, B$ ) to block both synaptic and extrasynaptic receptors. In accordance with previous data (Castro-Alamancos, 1999), gabazine application into the thalamus of mice $(n=3)$ disrupted the normal slow cortical oscillation and induced aberrant, large-amplitude regular activity in the cortex with a power spectrum peaking at $2.6 \mathrm{~Hz}$ (Fig. $5 A, B$ ). This indicates that, when all thalamic GABA-ARs are focally blocked, normal TC oscillations are disrupted. 
A
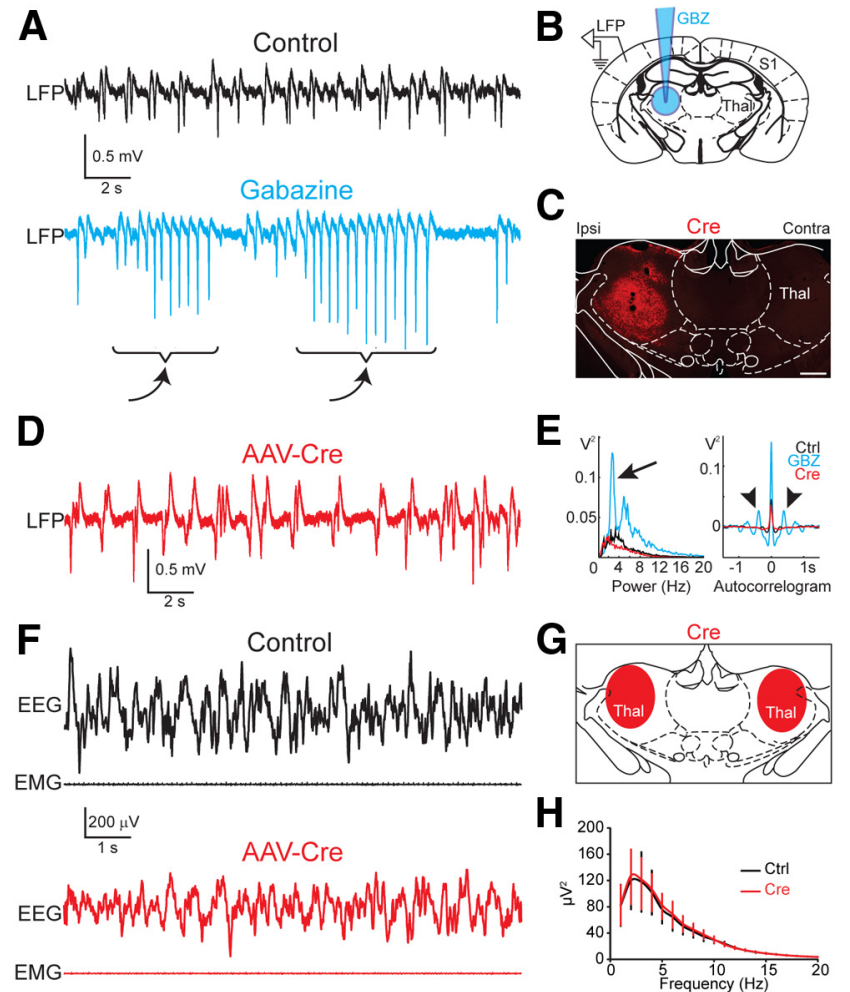

Figure 5. Removal of $\gamma 2-G A B A-A R s$ in the thalamus does not cause aberrant rhythmic cortical activity. $\boldsymbol{A}$, Cortical (primary somatosensory cortex, S1) LFP recordings before (control, black) and after unilateral administration of gabazine (blue) into somatosensory thalamus under ketamine/xylazine anesthesia. There are epileptiform bouts of activity (curved arrows) in the cortical LFP recordings after gabazine. $\boldsymbol{B}$, Scheme of the unilateral, thalamic (Thal), gabazine (GBZ) injection site. C, Low-power fluorescent image depicting (re immunostaining (red) after thalamic injection of AAV-Cre. Scale bar, $500 \mu \mathrm{m}$. D, The cortical LFP recorded from the ipsilateral S1 (red) after AAV-Cre injection to the thalamus is comparable with control $(\boldsymbol{A})$. $\boldsymbol{E}$, Power spectra (left) and autocorrelograms (right) of the cortical LFPs in control condition (black), after gabazine (blue) and AAV-Cre injection (red). There is a large central peak at $2.6 \mathrm{~Hz}$ (marked by arrow) and the side lobes (arrowheads) in the GBZ treated animal but not in (trl and (re cases. $\boldsymbol{F}$, In freely moving animals, slow oscillations are comparable in control (top black) and AAVCre-injected animals (top red) during NREM sleep. Bottom, Black and red traces represent the simultaneous EMG activity. G, Scheme of the bilateral thalamic injection of AAV-Cre in the freely moving animals. $\boldsymbol{H}$, Power spectrum of NREM sleep over $24 \mathrm{~h}$ from 4 animals each of the AAV-GFP and AAV-Cre groups. Data were binned into $1 \mathrm{~Hz}$ bins and analyzed statistically using univariate repeated-measures ANOVA with factor "group" and "bin," yielding $p>0.05$ for the group $\times$ bin interaction.

Next, we performed similar experiments using focal delivery of AAV-Cre (Fig. 5C) vectors instead of gabazine injection to examine whether deletion of synaptic receptors alone results in disturbed cortical activity. However, 3-8 weeks after viral delivery, selective deletion of only the synaptic GABA-ARs did not result in aberrant oscillations (Fig. $5 D ; n=9$ ). As a consequence, none of the cortical LFP autocorrelograms recorded from AAVCre-treated animals displayed the large central peaks, flanked by side lobes, which characterize the large amplitude, regular, rhythmic activity we observed after the injection of gabazine (Fig. 5E).

We also investigated the consequence of $\gamma 2$-GABA-AR deletion on oscillatory activity during natural sleep. After bilateral thalamic injection of AAV-Cre $(n=4)$ or AAV-GFP (as control, $n=4$ ), polysomnographic recordings yielded no sign of overt large-amplitude, aberrant activity during NREM sleep (Fig. $5 F, G)$ after 3 weeks of recovery in freely moving mice. Mean power spectra across $24 \mathrm{~h}$ of NREM sleep were indistinguishable for AAV-GFP and AAV-Cre animals (repeated-measures
ANOVA, $p>0.05$, Fig. $5 H$ ). Thus, in contrast to the pharmacological blockade of all GABA-ARs, the TC system produces normal oscillatory activity even when largely devoid of thalamic 2-GABA-ARs.

\section{Altered firing properties of TC cells in the absence of synaptic GABA-ARs}

Complementing the EEG and LFP recordings, we also examined the firing pattern of individual TC cells in ketamine/xylazineanesthetized mice through juxtacellular recordings (20-30 min) in two somatosensory thalamic nuclei known to have different inhibitory inputs (Pinault, 2004), the VB and the posterior nucleus (Po) (Barthó et al., 2002; Bokor et al., 2005; Wanaverbecq et al., 2008) (Fig. 6). Nuclear localizations of the juxtacellularly neurobiotin-labeled cells were post hoc identified using immunostaining against vGluT2 (Fig. 6D,I), whereas their phenotype was determined with Cre immunostaining (Fig. 6E,J).

The firing patterns of control, AAV-Cre-negative VB $(n=11)$ and $\mathrm{Po}(n=7)$ cells in mice were similar to those of rats under the same recording conditions (Slézia et al., 2011). More than $90 \%$ of spikes occurred in bursts. In accordance with our previous rat data, the average intraburst frequency of spikes in VB cells was significantly faster than in Po cells $(264.6 \pm 47.2 \mathrm{~Hz}$ vs $204.3 \pm$ $29.4 \mathrm{~Hz}, p<0.05$; Fig. $6 \mathrm{~A}, F)$.

Similar to controls, all AAV-Cre VB $(n=9)$ and Po $(n=8)$ cells were able to fire bursts of APs coupled to the rhythmic LFP activity (Fig. $6 B, G$ ). However, the properties of bursts were significantly altered in AAV-Cre cells and the alterations displayed nucleus-specific patterns (Fig. 6C,H).

In the absence of synaptic inhibition, the mean firing rate significantly decreased in case of AAV-Cre VB cells (control, $3 \pm$ $1.3 \mathrm{~Hz}$; AAV-Cre, $1.6 \pm 1.1 \mathrm{~Hz}, p<0.05$; Fig. 6C). This was largely because of the reduced number of burst events (burst incidence, $0.96 \pm 0.4 \mathrm{~Hz}$ in control vs $0.52 \pm 0.36 \mathrm{burst} / \mathrm{s}$ in AAV-Cre, $p<0.05)$. In addition, the intraburst frequencies of spikes in AAV-Cre VB cells were lowered by $42 \mathrm{~Hz}$ (16\%) (control, 264.6 \pm 47.2; AAV-Cre, $222.5 \pm 20.5 \mathrm{~Hz}, p<0.05$ ); however, the intraburst spike number did not change. As a consequence, the length of the AAV-Cre VB bursts increased significantly (burst length; $7.2 \pm 1 \mathrm{~ms}$ in control vs $8.7 \pm 1.7 \mathrm{~ms}$, in AAV-Cre, $p<0.05$; Fig. 6C).

In contrast to AAV-Cre $\mathrm{VB}$ cells, the mean firing rate of AAVCre Po cells was not altered (Fig. $6 H$ ). In these cells, the intraburst spike number displayed a slight decrease $(3.1 \pm 0.4$ spike/burst in control vs $2.7 \pm 0.5$ spike/burst in AAV-Cre Po cells, $p<0.05$; Fig. $6 H$ ). Because the intraburst frequency did not change, this resulted in a decrease of the overall burst length (control, $10.7 \pm$ $1.6 \mathrm{~ms}$; AAV-Cre, $9.0 \pm 1.9 \mathrm{~ms}, p<0.05$; Fig. $6 \mathrm{H}$ ).

These data show that TC cells retain low threshold bursts of APs in the absence of synaptic GABA-ARs, although the lack of synaptic inhibition slowed down the affected neurons, especially in VB.

\section{Spindle oscillations persist in the absence of synaptic GABA- ARs}

Next, we examined the effect of synaptic GABA-AR removal on spindle oscillations in the thalamus of urethane-anesthetized mice through multichannel silicone probes. The probes were labeled with DiI, and their depths were registered to determine the exact position of the electrode shanks relative to the infected regions (Fig. $7 A, D$ ). For these experiments, we chose urethane anesthesia because it provides a network activity generating spindles similar to natural sleep (Steriade et al., 1993) unlike ket- 
amine/xylazine anesthesia, during which short spindles are more prevalent (Slézia et al., 2011).

Spindles were detected in VB as transient rhythmic elevations of thalamic MUA, in the $7-15 \mathrm{~Hz}$ range, and could be quantitatively characterized (frequency, length, number of cycles, and occurrence; Fig. 7). We analyzed spindles in four experimental groups: noninjected wildtype, noninjected GABAAR $\gamma 2^{771}$ lox mice; AAV-Cre injected, contralateral to the thalamus injection (AAV-Cre, contralateral, Cre; Fig. $7 A-C)$ and AAV-Cre injected, ispilateral, within the injected zone (AAV-Cre, ipsilateral, Ctrl; Fig. 7D,E). The two noninjected groups did not differ in their quantitative measures and thus were grouped together (NonI, $n=7$ ). The occurrence of spindles was variable during the recordings because of the spontaneous fluctuation in the depth of anesthesia. To overcome this variability, we performed long recordings (129 $\pm 60 \mathrm{~min} / \mathrm{animal})$, during which we detected together 109,762 spindles (on average $5777 \pm 5509$ spindle/animal, $294 \pm 191$ spindle/channel).

Spindles in the noninjected groups occurred at $3.36 \pm 2.16$ event $/ \mathrm{min}$ (Fig. $7 F$ ). On average, the spindles consisted of $6.84 \pm 0.78$ cycles. The spindles lasted for $654 \pm 74 \mathrm{~ms}$ and the average intraspindle frequency was $10.46 \pm 0.35 \mathrm{~Hz}$, which is consistent with earlier data (Steriade et al., 1993).

In all experiments of the Cre group (8 penetrations in 6 animals), normal spindle activity was detected (Fig. $7 D, E$ ) in the AAV-Cre-infected zone. The quantitative analysis demonstrated that the spindles had similar rates of occurrence $(3.02 \pm 2.05$ event $/ \mathrm{min})$, similar numbers of spindle cycles $(6.30 \pm 0.39 \mathrm{~ms})$, and lengths ( $659 \pm 52 \mathrm{~ms}$ ) to control. The only consistent change due to the deletion of synaptic inhibition was a slight decrease $(10.5 \pm 0.5 \mathrm{~Hz}$ in Ctrl vs $9.6 \pm 0.4 \mathrm{~Hz}$ in Cre, $p<0.01)$ in intraspindle frequency (Fig. $7 F$ ).

We also followed on naturally occurring spindle activity through EEG recordings of NREM sleep in drug-free freely moving animals that previously received bilateral injections of either AAV-Cre or AAV-GFP (as control) vectors. NREM sleep states were analyzed with respect to the time course of power spectral densities at transitions to REM sleep. At these transitions, the power of frequencies between 5 and $25 \mathrm{~Hz}$ increases rapidly, notably at spindle-related EEG frequencies (Astori et al., 2011) (Fig. $8 A$ ). No change in the time course and power of this surge, averaged here for frequencies between 7 and $15 \mathrm{~Hz}$, was found in the AAV-Cre animals (Fig. 8B). These data demonstrate that oscillations in the spindle frequency range are preserved after the removal of synaptic inhibition from the thalamus.

\section{Discussion}

We show here that oscillatory activity in thalamic circuits is under the control of inhibition that involves $\gamma 2$ subunit-independent GABA-ARs. These receptors are activated as nRT cells switch from tonic to burst discharge and suggest a "firing patternspecific" form of inhibitory communication. Contrary to long-
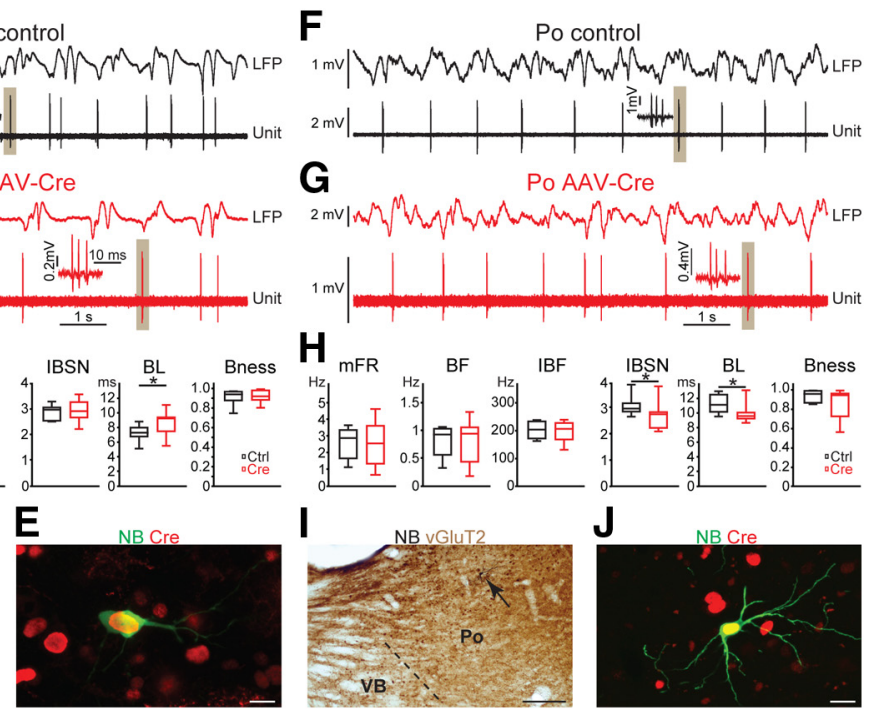

alterations in the firing properties of TC cells in vivo in the absence of synaptic GABA-ARs. $\boldsymbol{A}, \boldsymbol{B}$, Juxtacellular recordings of control (black, bottom) and AAV-Cre VB cells (red, bottom) together with cortical S1 LFP recordings (top in both cases) show typical burst firing. Shaded periods indicate selected bursts in expanded time scale. C, Analysis of the properties (green) shown in $\boldsymbol{B}$. Cre is localized to the nucleus. $\boldsymbol{F}, \boldsymbol{G}$, Juxtacellular recording of control and AAV-Cre Po cells together with Localization of the control Po cell shown in $\boldsymbol{F}$. Boundary is identified by vGluT2 immunostaining (brown). J, Confocal fluorescent image of the Cre-immunopositive Po cell shown in G. Scale bars: $\boldsymbol{D}, \boldsymbol{I}, 200 \mu \mathrm{m} ; \boldsymbol{E}, \boldsymbol{J}, 10 \mu \mathrm{m}$.

standing, previous views, conventional synaptic GABA-ARs are not absolutely required for TC rhythms. Phasic, nonsynaptic inhibition can efficiently drive TC cell rebound discharge and entrain slow oscillations and spindle waves during both sleep and anesthesia.

Our data demonstrate that, during burst firing of nRT cells, IPSCs in TC cells have both synaptic and nonsynaptic components in approximately equal proportions because $50 \%$ of the charge transfer remained intact after complete removal of the synaptic receptor pool in case of burst IPSCs. The remaining current had slow rise times and lacked fast-rising individual IPSCs, suggesting the contribution of extrasynaptic receptors. Most recently, an involvement of $\alpha 4$-containing GABA-ARs has been recognized during burst discharge at nRT-TC synapses in a manner that required GABA spillover, confirming our conclusions (Herd et al., 2013).

In the case of burst IPSCs, extrasynaptic receptors were recruited in a phasic, not in a tonic, manner. AP-mediated activation of extrasynaptic receptors, termed "GABA-A-slow" events, has already been demonstrated in several brain regions (Rossi and Hamann, 1998; Szabadics et al., 2007; Mańko et al., 2012). However, studying the extrasynaptic component of GABA-A-slow in isolation has not been possible with conventional pharmacological or genetic knock-out methods. Using virus-mediated gene knock-out of synaptic receptors, here we could quantitatively characterize the extrasynaptic component of GABA-AR responses and demonstrate that phasic extrasynaptic inhibition is mediated by burst discharge and powerful enough to drive global brain rhythms.

Our data disclosed a striking difference between eIPSCs when the presynaptic neuron fired in tonic as opposed to the burst 
A
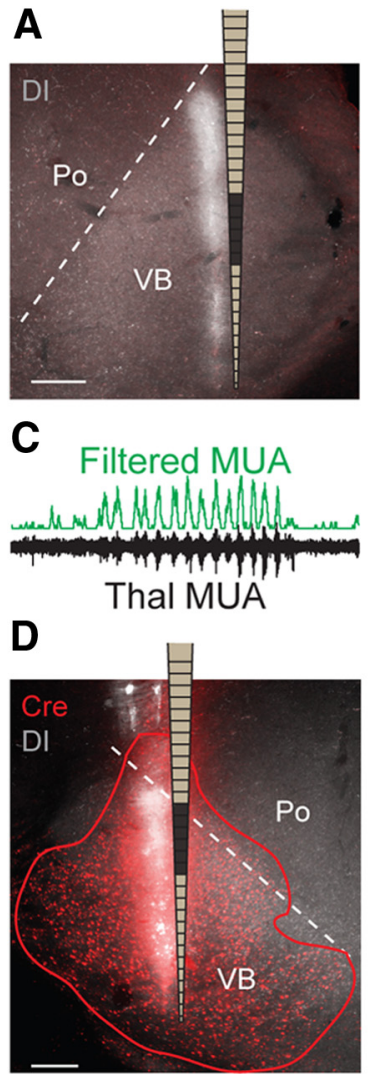

E

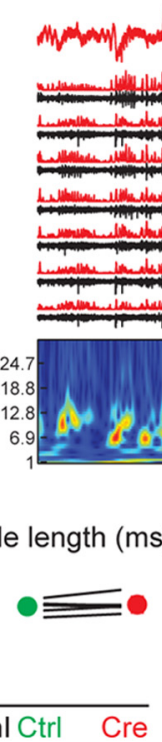

B

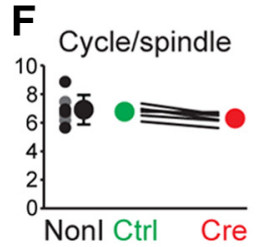

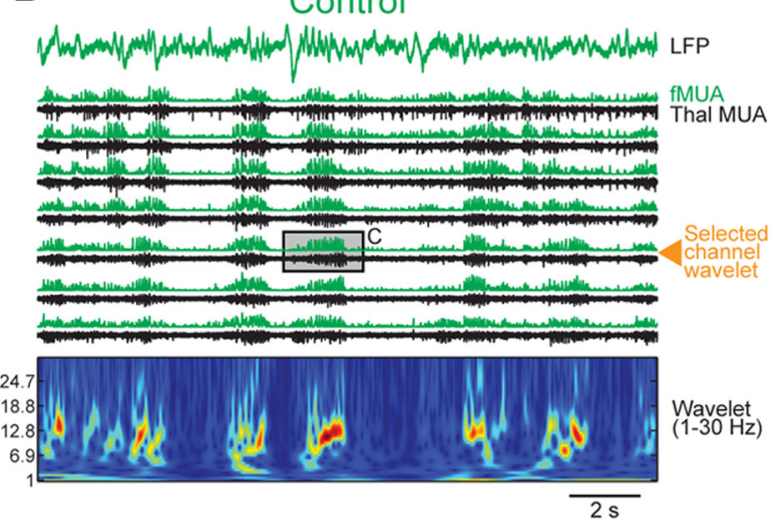

AAV-Cre
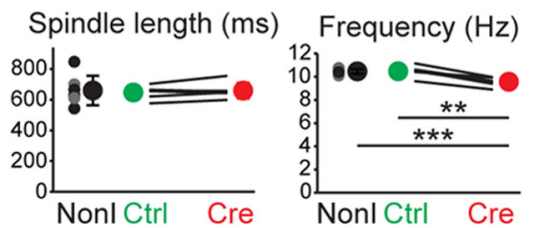

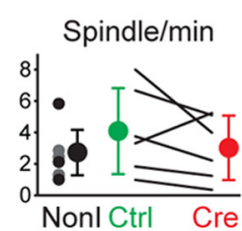

Figure 7. Thalamic spindle oscillations generated in the absence of synaptic GABA-ARs. A, Dil-labeled track of a linear 32channel silicon probe in the contralateral, noninfected VB. Dark gray in the schematic drawing of the silicon probe represents the position of the 7 channels shown in $\boldsymbol{B}$. B , Cortical LFP recording (top) and thalamic multiunit activity in 7 adjacent channels (middle) under urethane anesthesia. Black represents raw traces; green represents filtered MUA (fMUA; 7-15 Hz). At the bottom the wavelet analysis of the raw multiunit, activity is shown in the selected channel (orange arrowhead). Wavelets represent the color-coded power of the selected MUA between 1 and $30 \mathrm{~Hz}$. Warm colors represent high values. There is predominant activity in the spindle frequency range $(7-15 \mathrm{~Hz})$. C, Two-seconds-long trace of a thalamic multiunit spindle (marked by black framed area in the channel selected for wavelet in $\boldsymbol{B}$ ) before (black) and after filtering (green). $\boldsymbol{D}, \boldsymbol{E}$, Same arrangement as in $\boldsymbol{A}, \boldsymbol{B}$, respectively, for a recording in the ipsilateral, AAV-Cre-infected side of the same animal. The electrode track penetrates the AAV-Cre-infected region in $\boldsymbol{D}$. Spindles are abundant in the AAV-Cre-infected region as well. Scale bars: $\boldsymbol{A}, \boldsymbol{D}, 200 \mu \mathrm{m}$. $\boldsymbol{F}$, Quantitative analysis of spindles in noninjected (Nonl; $n=7)$, AAV-Cre contralateral (Cre-C; $n=6)$ and ipsilateral (Cre-l; $n=6)$ recordings. Only the frequency of spindles shows a slight decrease $(1 \mathrm{~Hz})$, which reaches statistical significance. All other spindle parameters were statistically not significant. Gray dots indicate recordings from noninjected wild-type $(n=3)$; black dots indicate recordings from noninjected GABAAR $\gamma 2{ }^{771}$ lox mice $(n=4)$. Error bars indicate \pm SD. ${ }^{* *} p<0.01$ (Student's $t$ test). ${ }^{* *} p<0.001$ (Student's $t$ test).

mode. The complete disappearance of sIPSCs and eIPSCs after the removal of synaptic receptors in TC cells indicates that inhibition caused by single or tonic APs was mediated entirely by synaptic receptors. In particular, up to $10 \mathrm{~Hz}$, tonic discharge did not recruit slow persistent currents (Wanaverbecq et al., 2008, Herd et al., 2013). In sharp contrast, during burst firing mode, a significant extrasynaptic receptor pool was additionally recruited that resulted in a strong increase of peak $\mathrm{Cl}^{-}$conductance (up to $\sim 10$-fold). According to Herd et al. (2013), extrasynaptic receptors contribute not only to burst IPSCs, but also prolong the decay time course of IPSCs after single APs. Small differences in the actual role of $\alpha 4$-GABA-ARs could vary according to the

preparation used. Herd et al. (2013) studied a complete $\alpha 4 \mathrm{KO}$, whereas in this study virally mediated gene knock-out was used in adult animals. Full KO techniques are more prone to induce compensatory changes, such as alterations in properties and exact location of remaining receptors. Intriguingly, however, this study mirrors our finding by showing that reduction of only extrasynaptic, but not synaptic GABA-ARs, also produces a $50 \%$ reduction in charge transfer.

Phasic, extrasynaptic inhibition was sufficient to promote rebound burst firing in TC cells, as demonstrated through command waveforms derived from burst IPSCs. This conclusion was also supported by the in vivo data showing burst firing in all TC neurons lacking synaptic GABA-ARs and preserved TC oscillations.

The burst IPSCs did not result from a temporal summation of phasic, conventional GABA-AR-mediated fast IPSCs. Instead, burst IPSCs reflect a rapid accumulation of GABA release that evokes phasic, nonsynaptic receptor activation in a manner not reached via repetitive tonic discharge up to tens of $\mathrm{Hz}$ (Wanaverbecq et al., 2008). As nRT-TC synapses are depressing, specific presynaptic release mechanisms activated during highfrequency discharge could contribute to the rapid increases in synaptic GABA levels, which remain the subject of further molecular characterization of nRT-TC synapses.

An unexpected change in our studies was a pronounced decrease in tonic inhibition and the associated increase in membrane resistance, without an apparent change in the expression of $\alpha 4$ subunits. One explanation for the decreased tonic conductance is the disappearance of phasic inhibition in the distal dendritic region of TC cells, which is indistinguishable from the tonic conductance at the somatic level (Farrant and Nusser, 2005). Other possibilities, such as homeostatic downregulation of ambient GABA levels or involvement of nonconventional GABA-AR pools, remain to be determined. Based on our data, we currently cannot exclude the contribution of synaptic receptors to tonic inhibition.

Our experimental approach provided a unique opportunity to study the firing pattern of individual neurons lacking synaptic receptors embedded into a neuronal network oscillating normally. We performed the experiments in two thalamic nuclei, VB and Po, known to have distinct excitatory and inhibitory connectivity (Barthó et al., 2002; Bokor et al., 2005; Wanaverbecq et al., 2008; Groh et al., 2013). We found significant internuclear differences in response to the removal of synaptic GABAergic inhibition. Major changes were found in the VB, including a 

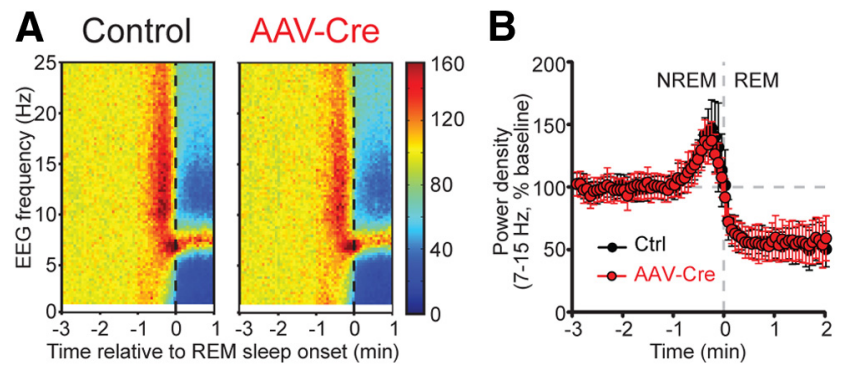

Figure 8. Normal spindle power density without thalamic $\gamma 2-G A B A-A R s$ during natural sleep. A, Color-coded heat maps of normalized EEG power between 0.75 and $25 \mathrm{~Hz}$ in $0.25 \mathrm{~Hz}$ bins during the NREM-to-REM sleep transitions in control $(n=4)$ and in AAV-Cre-infected mice $(n=4)$. Black dashed lines at time 0 indicate REM sleep onset. $\boldsymbol{B}$, Average mean EEG power time course between 7 and $15 \mathrm{~Hz}$ for all NREM-to-REM sleep transitions in the light phase. Data are normalized to the mean power in the time interval from -3 to -1 minute before the transition. Each data point corresponds to a 4 s epoch and is presented as mean \pm SD.

significant drop in firing frequency, whereas changes in the Po were less prevalent. We attribute these differences to the distinct connectivity and activity pattern of the two nuclei (Hoogland et al., 1991; Groh et al., 2013). In case of VB cells, during the Up states of ketamine/xylazine induced slow oscillation, the intracellular activity is dominated by nRT-mediated rhythmic inhibition, whereas in case of Po cells fast rising EPSPs arising from layer 5 pyramidal cells determine Po activity under similar conditions (Groh et al., 2013). In agreement with these data, removal of synaptic inhibition affected VB cells to a much greater extent than Po cells. Thus, we conclude that the exact role of synaptic inhibition in controlling firing activity depends on the neuronal network the cell is embedded.

Thalamic application of GABA-AR antagonists, which block both synaptic and extrasynaptic receptors, disrupts the major TC oscillation and evokes aberrant, large-amplitude activity in ferrets and rats (Bal et al., 1995a; Castro-Alamancos, 1999), an observation that we replicated now in mice. These studies demonstrate that GABA-ARs in the thalamus have a critical role in supporting $\mathrm{TC}$ oscillations and GABA-B receptors alone cannot maintain normal rhythmic activity. In this study, we compared the consequences of full pharmacological blockade of GABA-ARs with those induced by virally mediated knock-out of synaptic GABA-ARs. Whereas total pharmacological blockade of thalamic GABA-ARs disrupts the major TC oscillations (Kim et al., 1995; Castro-Alamancos, 1999), the selective virus-mediated deletion of $\gamma 2$-GABA-ARs did not affect the normal brain rhythms, and removal of only the synaptic GABA-ARs did not produce aberrant cortical activity. These experiments were performed under two different kinds of anesthesia (ketamine/xylazine and urethane) and in drug-free conditions as well, with identical outcomes, indicating that particular experimental conditions did not affect the results. Our data thus show that activation of extrasynaptic receptors by GABA spillover during nRT bursts alone generates sufficient amount of inhibition to maintain normal slow cortical oscillations and prevent the development of aberrant rhythmic activity.

A surprising outcome of our experiments was that spindle activity and EEG hallmarks of sleep spindles were also preserved in the brain of AAV-Cre-infected mice, indicating that relatively fast oscillations $(7-15 \mathrm{~Hz})$ can persist in the absence of synaptic receptors. The data demonstrate that slow GABA-A currents alone are able to maintain normal spindles with statistically similar occurrence and duration as in the intact brain. Despite the reduced charge transfer of burst IPSCs, after the removal of syn- aptic receptors, the phasic, extrasynaptic component of the burst IPSCs provided enough hyperpolarization to allow rebound burst discharges in TC cells. Indeed, in TC cells, a relatively small proportion of T-type $\mathrm{Ca}^{2+}$ channels' deinactivation is sufficient for rebound burst generation (Dreyfus et al., 2010). As the frequency of rebound burst depends on the integrated membrane hyperpolarization imposed by nRT-IPSPs (Bal et al., 1995b), we found a slightly but significantly slower mean spindle frequency $(\sim 1 \mathrm{~Hz}$ decrease). In our experiments, the time course of thalamic GABA-A slow/burst IPSCs was $100-120 \mathrm{~ms}$, which is well suited to pace a rhythm in the spindle frequency range $(7-15 \mathrm{~Hz})$ via the rebound mechanism. Thus, we propose here that this peculiar form of inhibition displaying dual synaptic and extrasynaptic nature was evolved to entrain a stable oscillation in the $7-15 \mathrm{~Hz}$ frequency range.

In conclusion, in the present study, we identified a discharge mode-specific mechanism of inhibition at a long-studied synapse implicated in a classical pacemaker activity. The synapse's main function is to synchronize TC cells to recruit them into oscillatory activity. Our data imply a complex organization of the synapse and a fine-tuned cooperation between different GABA-ARs according to the discharge mode. The molecular constitution of thalamic GABA-ARs is central to our understanding of TC synchronization during sleep, as synaptic GABA-ARs are the targets of many hypnotic and sedative drugs (Winsky-Sommerer, 2009). Here we propose that a nonsynaptic receptor entrains major sleep-associated TC oscillations in a phasic manner. Our findings provide a compelling explanation for the specific roles of different GABA-ARs in distinct behavioral states and thus open novel avenues to the development of drugs that act specifically on receptor subtypes contributing to burst IPSCs. These would have the unique potential to boost sleep yet protect phasic inhibition mediated by tonic discharge and associated wake-related functions.

\section{References}

Astori S, Wimmer RD, Prosser HM, Corti C, Corsi M, Liaudet N, Volterra A, Franken P, Adelman JP, Lüthi A (2011) The CaV3.3 calcium channel is the major sleep spindle pacemaker in thalamus. Proc Natl Acad Sci U S A 108:13823-13828. CrossRef Medline

Bal T, von Krosigk M, McCormick DA (1995a) Role of the ferret perigeniculate nucleus in the generation of synchronized oscillations in vitro. J Physiol 483:665-685. Medline

Bal T, von Krosigk M, McCormick DA (1995b) Synaptic and membrane mechanisms underlying synchronized oscillations in the ferret lateral geniculate nucleus in vitro. J Physiol 483:641-663. Medline

Barthó P, Freund TF, Acsády L (2002) Selective GABAergic innervation of thalamic nuclei from zona incerta. Eur J Neurosci 16:999-1014. CrossRef Medline

Belelli D, Harrison NL, Maguire J, Macdonald RL, Walker MC, Cope DW (2009) Extrasynaptic GABAA receptors: form, pharmacology, and function. J Neurosci 29:12757-12763. CrossRef Medline

Blatow M, Rozov A, Katona I, Hormuzdi SG, Meyer AH, Whittington MA, Caputi A, Monyer H (2003) A novel network of multipolar bursting interneurons generates theta frequency oscillations in neocortex. Neuron 38:805-817. CrossRef Medline

Bokor H, Frère SG, Eyre MD, Slézia A, Ulbert I, Lüthi A, Acsády L (2005) Selective GABAergic control of higher-order thalamic relays. Neuron 45: 929-940. CrossRef Medline

Brickley SG, Mody I (2012) Extrasynaptic GABA(A) receptors: their function in the CNS and implications for disease. Neuron 73:23-34. CrossRef Medline

Brickley SG, Cull-Candy SG, Farrant M (1999) Single-channel properties of synaptic and extrasynaptic GABAA receptors suggest differential targeting of receptor subtypes. J Neurosci 19:2960-2973. Medline

Bright DP, Aller MI, Brickley SG (2007) Synaptic release generates a tonic $\mathrm{GABA}(\mathrm{A})$ receptor-mediated conductance that modulates burst preci- 
sion in thalamic relay neurons. J Neurosci 27:2560-2569. CrossRef Medline

Bright DP, Renzi M, Bartram J, McGee TP, MacKenzie G, Hosie AM, Farrant M, Brickley SG (2011) Profound desensitization by ambient GABA limits activation of $\delta$-containing GABAA receptors during spillover. J Neurosci 31:753-763. CrossRef Medline

Capogna M, Pearce RA (2011) GABA A slow: causes and consequences. Trends Neurosci 34:101-112. CrossRef Medline

Castro-Alamancos MA (1999) Neocortical synchronized oscillations induced by thalamic disinhibition in vivo. J Neurosci 19:RC27. Medline

Chandra D, Jia F, Liang J, Peng Z, Suryanarayanan A, Werner DF, Spigelman I, Houser CR, Olsen RW, Harrison NL, Homanics GE (2006) GABAA receptor alpha 4 subunits mediate extrasynaptic inhibition in thalamus and dentate gyrus and the action of gaboxadol. Proc Natl Acad Sci U S A 103:15230-15235. CrossRef Medline

Cobb SR, Buhl EH, Halasy K, Paulsen O, Somogyi P (1995) Synchronization of neuronal activity in hippocampus by individual GABAergic interneurons. Nature 378:75-78. CrossRef Medline

Cope DW, Hughes SW, Crunelli V (2005) GABAA receptor-mediated tonic inhibition in thalamic neurons. J Neurosci 25:11553-11563. CrossRef Medline

Crandall SR, Govindaiah G, Cox CL (2010) Low-threshold Ca ${ }^{2+}$ current amplifies distal dendritic signaling in thalamic reticular neurons. J Neurosci 30:15419-15429. CrossRef Medline

Dani A, Huang B, Bergan J, Dulac C, Zhuang X (2010) Neurotechnique superresolution imaging of chemical synapses in the brain. Neuron 68: 843-856. CrossRef Medline

Dreyfus FM, Tscherter A, Errington AC, Renger JJ, Shin HS, Uebele VN, Crunelli V, Lambert RC, Leresche N (2010) Selective T-type calcium channel block in thalamic neurons reveals channel redundancy and physiological impact of I(T) window. J Neurosci 30:99-109. CrossRef Medline

Essrich C, Lorez M, Benson JA, Fritschy JM, Lüscher B (1998) Postsynaptic clustering of major GABAA receptor subtypes requires the gamma 2 subunit and gephyrin. Nat Neurosci 1:563-571. CrossRef Medline

Farrant M, Nusser Z (2005) Variations on an inhibitory theme: phasic and tonic activation of GABA(A) receptors. Nat Rev Neurosci 6:215-229. CrossRef Medline

Franken P, Malafosse A, Tafti M (1998) Genetic variation in EEG activity during sleep in inbred mice. Am J Physiol 275:R1127-R1137. Medline

Groh A, Bokor H, Mease RA, Plattner VM, Hangya B, Stroh A, Deschenes M, Acsády L (2013) Convergence of cortical and sensory driver inputs on single thalamocortical cells. Cereb Cortex. Advance online publication. Retrieved July 3, 2013. doi: 10.1093/cercor/bht173. CrossRef Medline

Hamann M, Rossi DJ, Attwell D (2002) Tonic and spillover inhibition of granule cells control information flow through cerebellar cortex. Neuron 33:625-633. CrossRef Medline

Herd MB, Brown AR, Lambert JJ, Belelli D (2013) Extrasynaptic GABA(A) receptors couple presynaptic activity to postsynaptic inhibition in the somatosensory thalamus. J Neurosci 33:14850-14868. CrossRef Medline

Hoogland PV, Wouterlood FG, Welker E, Van der Loos H (1991) Ultrastructure of giant and small thalamic terminals of cortical origin: a study of the projections from the barrel cortex in mice using Phaseolus vulgaris leuco-agglutinin (PHA-L). Exp Brain Res 87:159-172. Medline

Kim U, Bal T, McCormick DA (1995) Spindle waves are propagating synchronized oscillations in the ferret LGNd in vitro. J Neurophysiol 74: 1301-1323. Medline

Mańko M, Bienvenu TC, Dalezios Y, Capogna M (2012) Neurogliaform cells of amygdala: a source of slow phasic inhibition in the basolateral complex. J Physiol 590:5611-5627. CrossRef Medline

Nusser Z, Sieghart W, Somogyi P (1998) Segregation of different GABAA receptors to synaptic and extrasynaptic membranes of cerebellar granule cells. J Neurosci 18:1693-1703. Medline

Pinault D (1996) A novel single-cell staining procedure performed in vivo under electrophysiological control: morpho-functional features of juxtacellularly labeled thalamic cells and other central neurons with biocytin or Neurobiotin. J Neurosci Methods 65:113-136. CrossRef Medline

Pinault D (2004) The thalamic reticular nucleus: structure, function and concept. Brain Res Brain Res Rev 46:1-31. CrossRef Medline

Pirker S, Schwarzer C, Wieselthaler A, Sieghart W, Sperk G (2000) GABA(A) receptors: immunocytochemical distribution of 13 subunits in the adult rat brain. Neuroscience 101:815-850. CrossRef Medline

Porcello DM, Huntsman MM, Mihalek RM, Homanics GE, Huguenard JR (2003) Intact synaptic GABAergic inhibition and altered neurosteroid modulation of thalamic relay neurons in mice lacking $\delta$ subunit. J Neurophysiol 89:1378-1386. Medline

Rossi DJ, Hamann M (1998) Spillover-mediated transmission at inhibitory synapses promoted by high affinity alpha6 subunit GABA(A) receptors and glomerular geometry. Neuron 20:783-795. CrossRef Medline

Sanchez-Vives MV, McCormick DA (2000) Cellular and network mechanisms of rhythmic recurrent activity in neocortex. Nat Neurosci 3:10271034. CrossRef Medline

Schindelin J, Arganda-Carreras I, Frise E, Kaynig V, Longair M, Pietzsch T, Preibisch S, Rueden C, Saalfeld S, Schmid B, Tinevez JY, White DJ, Hartenstein V, Eliceiri K, Tomancak P, Cardona A (2012) Fiji: an opensource platform for biological-image analysis. Nat Methods 9:676-682. CrossRef Medline

Slézia A, Hangya B, Ulbert I, Acsády L (2011) Phase advancement and nucleus-specific timing of thalamocortical activity during slow cortical oscillation. J Neurosci 31:607-617. CrossRef Medline

Steriade M, Nuñez A, Amzica F (1993) Intracellular analysis of relations between the slow $(<1 \mathrm{~Hz})$ neocortical oscillation and other sleep rhythms of the electroencephalogram. J Neurosci 13:3266-3283. Medline

Szabadics J, Tamás G, Soltesz I (2007) Different transmitter transients underlie presynaptic cell type specificity of GABA A, slow and GABA A, fast. Proc Natl Acad Sci U S A 104:14831-14836. CrossRef Medline

Tretter V, Ehya N, Fuchs K, Sieghart W (1997) Stoichiometry and assembly of a recombinant GABAA receptor subtype. J Neurosci 17:2728-2737. Medline

von Krosigk M, Bal T, McCormick DA (1993) Cellular mechanisms of a synchronized oscillation in the thalamus. Science 261:361-364. CrossRef Medline

Wanaverbecq N, Bodor AL, Bokor H, Slézia A, Lüthi A, Acsády L (2008) Contrasting the functional properties of GABAergic axon terminals with single and multiple synapses in the thalamus. J Neurosci 28:11848-11861. CrossRef Medline

Wei W, Zhang N, Peng Z, Houser CR, Mody I (2003) Perisynaptic localization of $\delta$ subunit-containing GABA(A) receptors and their activation by GABA spillover in the mouse dentate gyrus. J Neurosci 23:10650-10661. Medline

Wimmer RD, Astori S, Bond CT, Rovó Z, Chatton JY, Adelman JP, Franken P, Lüthi A (2012) Sustaining sleep spindles through enhanced SK2channel activity consolidates sleep and elevates arousal threshold. J Neurosci 32:13917-13928. CrossRef Medline

Winsky-Sommerer R (2009) Role of GABAA receptors in the physiology and pharmacology of sleep. Eur J Neurosci 29:1779-1794. CrossRef Medline

Wulff P, Ponomarenko AA, Bartos M, Korotkova TM, Fuchs EC, Bähner F, Both M, Tort AB, Kopell NJ, Wisden W, Monyer H (2009) Hippocampal theta rhythm and its coupling with gamma oscillations require fast inhibition onto parvalbumin-positive interneurons. Proc Natl Acad Sci U S A 106:3561-3566. CrossRef Medline 